\title{
Advanced Scalar Control with FPGA Device for Pumping Photovoltaic System
}

\author{
Dhafer Mezghani ${ }^{1}$, Hichem Othmani* ${ }^{1,2}$ and Abdelkader Mami ${ }^{1}$ \\ ${ }^{1}$ University of Tunis Manar, National Engineering School of Tunis, LR-11-ES20, \\ Laboratory of Analyze, Conception and Control of Systems, BP 37, Belvedere, \\ Tunis 1002, Tunisia \\ ${ }^{2}$ University of Tunis El Manar, Faculty of Sciences of Tunis, Department of \\ Physics, The university Campus of Farhat Hached B.P. $n^{\circ} 94$ - Rommana 1068 \\ Tunis, Tunisia \\ dhafer.mezghanni@gmail.com,hichemothmani@enit.utm.tn, \\ abdelkader.mami@gmail.com
}

\begin{abstract}
This work presents a virtual prototype for studying and simulation of pumping photovoltaic installation's scalar control. The implementation is supposed to be realized in FPGA device. The simulation was conducted using the Matlab/Simulink and the Active$H D L$ programs. While the photovoltaic generator /inverter/motor dynamic is executed in the Matlab, the Active-HDL performs the scalar control which is written in VHDL-code. both of the programs work in Co-simulation mode provided by the Active-HDL block-set in the simulink.
\end{abstract}

Keywords: FPGA, Co_simulation, MPPT (Perturb and Observe), Pumping System, Scalar Control, Photovoltaic

\section{Introduction}

The increasing of the world energy request, due to the modern industrial society and population growth, is motivating a lot of investments in alternative energy solution [2]. Photovoltaic (PV) is an attractive source of energy. In fact, this source is one of the most important renewable-energy source that has been increasing worldwide year-by year [1]. Water pumping represents one of the most active areas of research using photovoltaic (PV).

The photovoltaic pumping system used for many applications like irrigation, particularly in the isolated areas [3]. In this paper a model construction and verification of scalar control of pumping photovoltaic installation has been proposed in order to be implemented in a field -programmable gate arrays (FPGA) chips. In the last decade, different control strategies have been proposed in literature [2] [3]. Until recently, the different strategies have been implemented in microcontroller and digital signal processor (DSPs). While DSPs can provide a reasonable performance, they do not afford the high degree of flexibility that field -programmable gate arrays (FPGA) chip offer today [4]. In addition to that, FPGA can also be reprogrammed at any time [1]. In addition, this reprogrammability can provide a high level of flexibility.

This work shows the simulation of scalar control technique using Matlab with Active_HDL Simultaneously, allowing a global Co-simulation of the induction motor and the scalar strategy coded in VHDL. With the result of this work, it is expected to demonstrate the flexibility of the simulation tool [9]. 


\section{Materials and Models of the Photovoltaic Installation}

The hardware platform used for testing and judging the robustness of the adopted order is given by the Figure 3 .

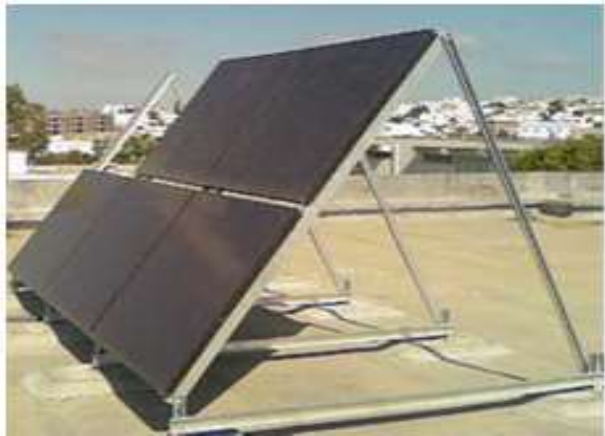

Figure 1-a. Photovoltaic Generator

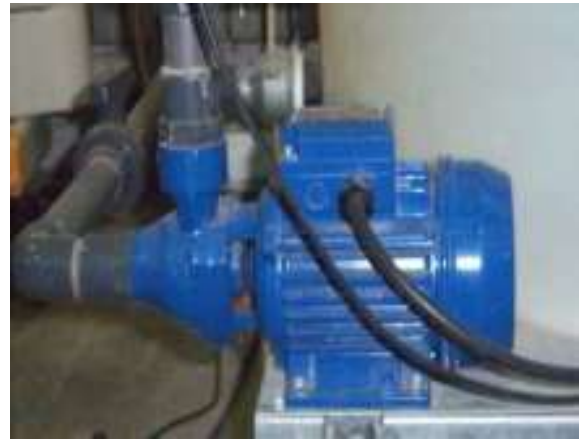

Figure 1-b. Induction Motor-pump

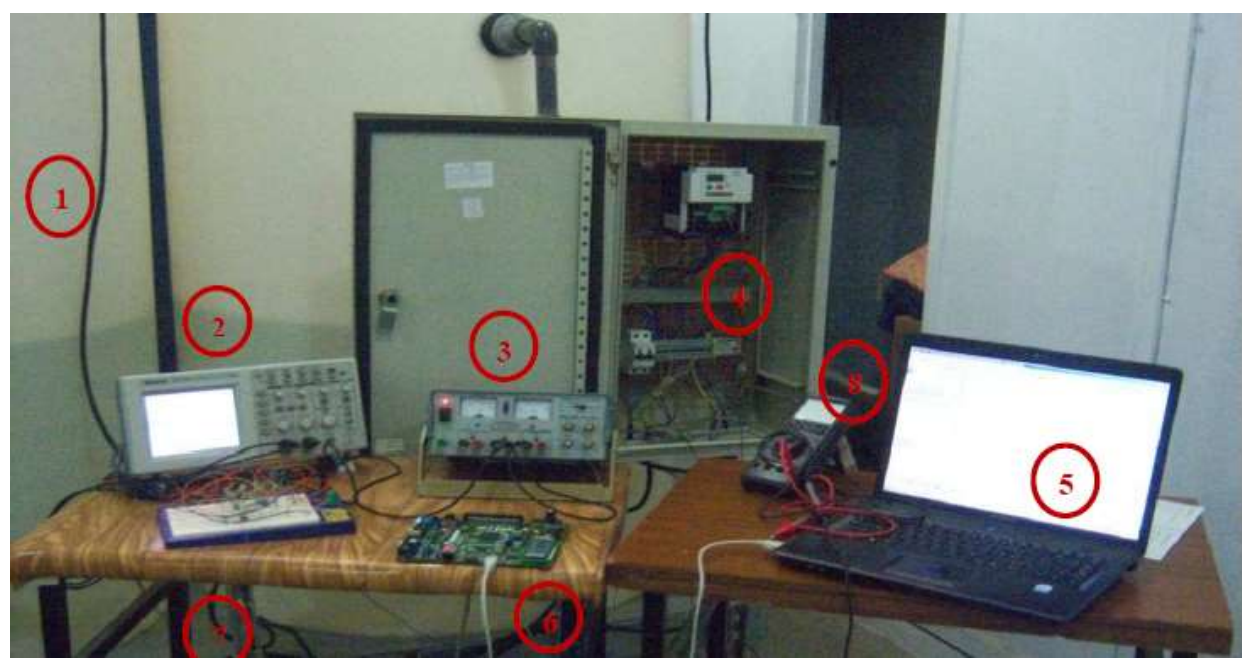

Figure 1-c. Hydraulic Circuit and Acquisition Devices

In order to validate the model of various components of the pumping hybrid system and to simulate the real behavior of hybrid system, it's necessary to have the experimental results based on the acquisitions carried out through a device given by elements 2,7 and 8 in the Figure 1-c.

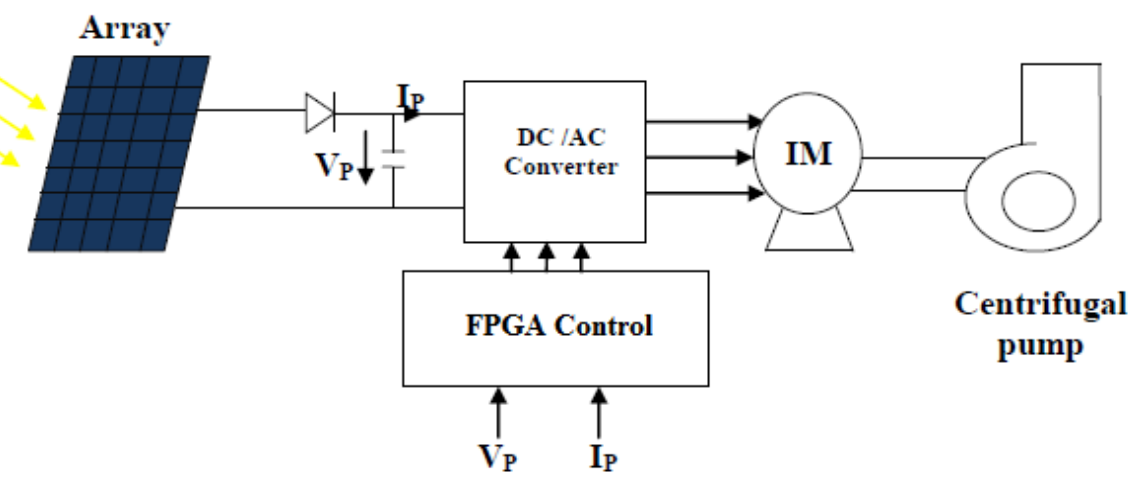

Figure 2. Photovoltaic Pumping System

For the measurement and acquisition of various sizes, we have a plug-in analog inputs and outputs and implementation of different controls (MPPT and Scalar control) this is 
given by the Spartan FPGA device (element 6), it uses correspondent information of the insulation Ec and the external ambient temperature $\mathrm{Ta}$ and it generates a statoric frequency to the frequency converter (element 4) such that the maximum power is transferred to the hydraulic circuit (element 1). The element 5 is used to save the monthly and the annual data in file excel. The three phases inverter is fed to photovoltaic generator (Figure 1-a), in addition to that, the centrifugal pump is coupled to the induction motor (Figure 1-b). So, this system can be represented by Figure 2. This work is based upon the knowledge of the action of the various parts of the system models.

\subsection{Modeling of the Photovoltaic Generator}

Solar cell generates electric power when illuminated by sun light or artificial light. Figure. 2 represents the simplified equivalent electric circuit of a photovoltaic cell defined by the following equations:

$$
\mathrm{I}_{\mathrm{p}}=\mathrm{Ipht}-\mathrm{Isst}\left(\exp \left(\frac{\mathrm{q}\left(\mathrm{V}_{\mathrm{p}}\right)}{\mathrm{n}_{\mathrm{tKT}}}\right)-1\right)
$$

With,

$$
\begin{gathered}
I_{p h t}=\left(I_{c c}\left(\frac{E_{c}}{E_{c r e f}}\right)+j \frac{E_{c}\left(T_{a}-T_{\text {ref }}\right)}{E_{c r e f}}\right) \\
\text { And } \quad I_{s s t}=I_{s} T_{p}{ }^{3} \exp \left\{\frac{-E_{g}}{K T_{p}}\right\}
\end{gathered}
$$

Where ni is the ideality factor of the cell; $\mathrm{K}$ is the Boltzmann constant; $\mathrm{q}$ is the electric charge; Ipht is the photocurrent; Icc is the short-circuit current under standard conditions (Ecref $=1000 \mathrm{~W} / \mathrm{m} 2$ and $\left.\operatorname{Tref}=25^{\circ} \mathrm{C}\right) ; \mathrm{Ipv}$, photovoltaic current; Vp, photovoltaic voltage, $\mathrm{Ec}$ is the irradiance, $\mathrm{Ta}$ is the ambient temperature, $\mathrm{j}$ is the coefficient of short-circuit current/temperature $\left(0.0017 \mathrm{~A} /{ }^{\circ} \mathrm{C}\right)$

Figure. 2 shows the measured current-voltage (I-V) and power voltage (P-V) characteristics. It can be noticed that, at fixed irradiance and temperature, there is a unique point corresponding to the maximum power that the PV array can generate [1].

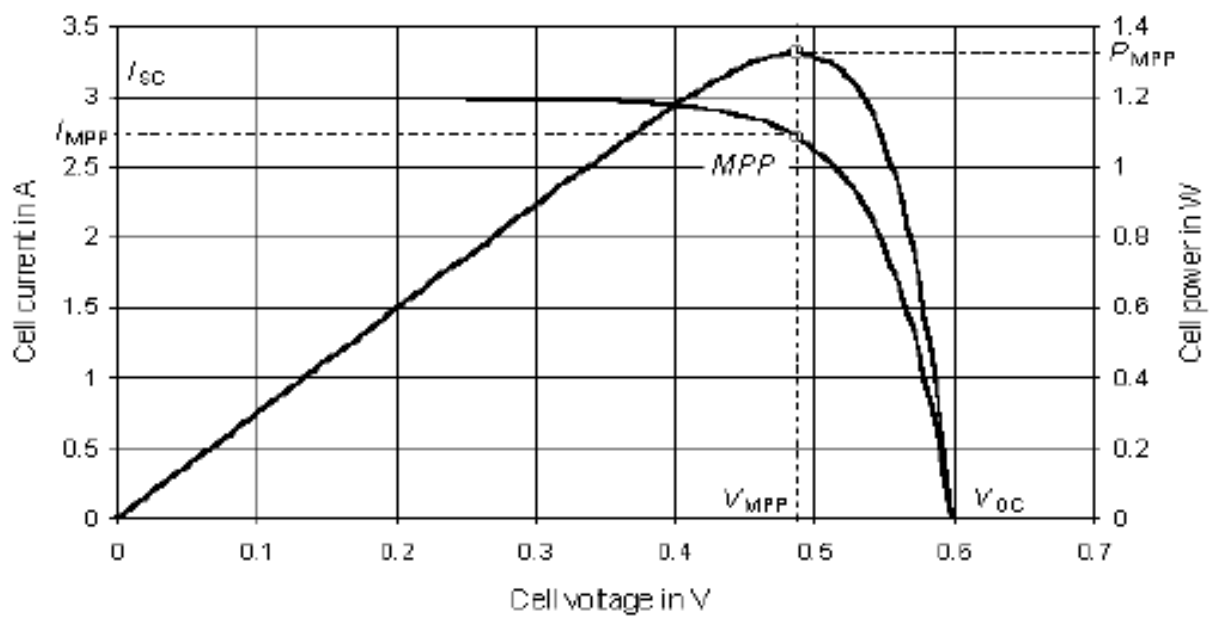

Figure 3. Current- Voltage and Power- Voltage Characteristics with MPP

The Various publications on MPPT controls appear in the literature for 40 years [5]. We can find many efficient algorithms that allow us to determine the maximum power point MPP , we are interested in controller Perturb and Observe (P \& O) [6 ], [7 ] whose 
principle is to disrupt the voltage $\mathrm{Vp}$ around its initial value and analyze the behavior of the power PV variation that results [1].

\subsection{Modeling of the Voltage Inverter}

The DC-AC inverters are interfaces providing an adaptation between the photovoltaic generator and the pump unit. These converters consist of electronic components behave as switches with two possible logic states: open or closed. A natural PWM switching technique is used to drive the three- phase's voltage shown in Figure-4.

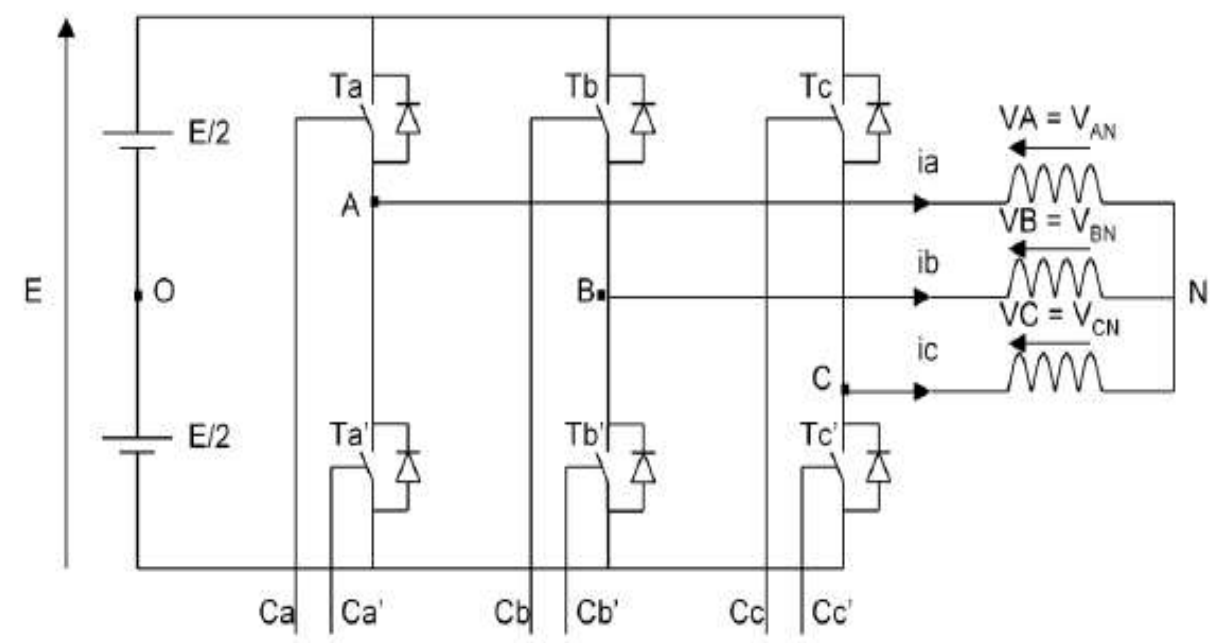

Figure 4. Three Phase's Inverter

The three phase's voltage is composed of three arms each of which contains two switches. Each switch is composed of an IGBT and a diode connected ant parallel. E is the voltage at the input of the inverter. Function $\mathrm{Ck}$ and $\mathrm{Ck}, \mathrm{K}=\mathrm{a}, \mathrm{b}, \mathrm{c}$; are a binary command which represent the state of switches of the arms.

- if $\mathrm{Ck}=1$, the switch Tk is closed, $\mathrm{k}=\mathrm{a}, \mathrm{b}, \mathrm{c}$

- if $\mathrm{Ck}=0$, the switch Tk is open, $\mathrm{k}=\mathrm{a}, \mathrm{b}, \mathrm{c}$

- if $\mathrm{Ck}^{\prime}=1$, the switch Tk' is closed, $\mathrm{k}=\mathrm{a}, \mathrm{b}, \mathrm{c}$

- if $\mathrm{Ck}^{\prime}=1$, the switch Tk' is open, $\mathrm{k}=\mathrm{a}, \mathrm{b}, \mathrm{c}$

During the operation of the inverter, it must be ensured that there is no short-circuit of the E voltage source. This is why, it is necessary that the switches of the same arms Tk and $\mathrm{Tk}^{\prime}, \mathrm{K}=\mathrm{a}, \mathrm{b}, \mathrm{c}$; are controlled in a complementary manner. The expression of the voltages o the induction machine relative to neutral is given by :

$$
\left(\begin{array}{l}
V_{A N} \\
V_{B N} \\
V_{C N}
\end{array}\right)=\frac{E}{3}\left(\begin{array}{ccc}
2 & -1 & -1 \\
-1 & 2 & -1 \\
-1 & -1 & 2
\end{array}\right)\left(\begin{array}{l}
C_{a} \\
C_{b} \\
C_{c}
\end{array}\right)
$$




\subsection{Modeling of the Induction Motor}

The mathematical dynamic model of the asynchronous motor is described in [5-6] [1617], by:

$$
\begin{gathered}
v_{d s}=R_{s} i_{d s}+\frac{d \Phi_{d s}}{d t}-\omega \Phi_{q s} \\
v_{q s}=R_{s} i_{q s}+\frac{d \Phi_{q s}}{d t}+\omega \Phi_{d s} \\
0=R r i_{d r}+\frac{d \Phi_{d r}}{d t}-\left(\omega-n_{p} \Omega_{m}\right) \Phi_{q s} \\
0=R r i_{q r}+\frac{d \Phi_{q r}}{d t}+\left(\omega-n_{p} \Omega_{m}\right) \Phi_{d s}
\end{gathered}
$$

The electromagnetic torque Te is expressed by:

$$
\mathrm{T}_{\mathrm{e}}=\mathrm{n}_{\mathrm{p}}^{\frac{\mathrm{Lm}}{\mathrm{Lr}}}\left(\mathrm{i}_{\mathrm{qs}} \Phi_{\mathrm{dr}}-\mathrm{i}_{\mathrm{ds}} \Phi_{\mathrm{qr}}\right)
$$

where Ls, Lr, Rs, Rr and Lm are: stator and rotor main inductances, resistances and mutual inductances respectively., Ids, $\Phi \mathrm{ds}$ are d-axis stator current and rotor flux and Iqs,,$\Phi_{\mathrm{qr}}$ are q-axis stator current and rotor flux, and $\mathrm{np}$ is the number of pole pairs, $\Omega_{\mathrm{m}}$ is the mechanical speed, $\omega$ is the electrical pulsation.

\subsection{Modeling of the Hydraulic Circuit}

In this work, the pump used is of centrifugal pump. The equation characteristic of the hydraulic network is given by:

$$
H_{\text {pump }}=b_{0} \Omega_{m}^{2}+b_{1} \Omega_{m} Q+b_{2} Q^{2}
$$

And

$$
H_{\text {circuit }}=\Psi Q^{2}
$$

The operating point of the installation is the intersection of two Hpump characteristics (Q) at constant speed and Hcircuit $(\mathrm{Q})$ defined by the flow rate $\mathrm{Q}$ on which the pump is automatically adjusted. The figure below shows the evolution of the operating point for several speeds.

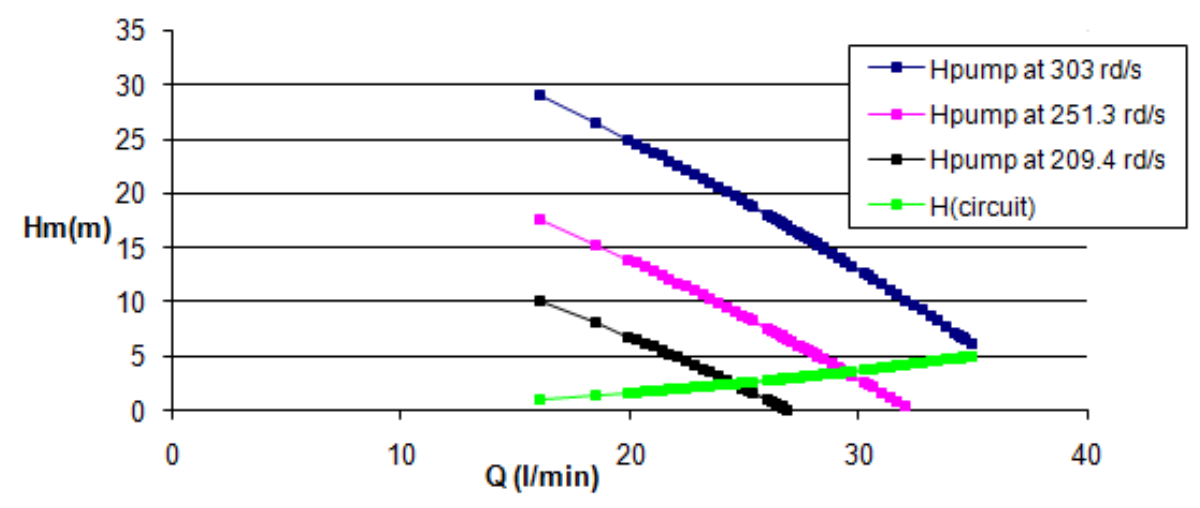

Figure 5. Operating Point of Hydraulic Circuit for Different Speeds

These Tests performed on the hydraulic circuit used to establish a law of similarity between the flow rate $\mathrm{Q}$ and the mechanical speed $\Omega \mathrm{m}$ given by: 


$$
Q=\left(\frac{-b_{1}-\sqrt{b_{1}^{2}-4 b_{0}^{2}\left(b_{2}-\Psi\right)}}{2\left(b_{2}-\Psi\right)}\right) \Omega_{m}=\left(\frac{Q_{n o m}}{\Omega_{n o m}}\right) \Omega_{m} \approx\left(\frac{35.6}{303}\right) \Omega_{m}
$$

The pump efficiency is defined as the ratio of the pump to the fluid to the shaft mechanical power and is given by (10):

$$
\eta_{p}=\frac{P_{h y}}{P_{\text {mec }}}=\frac{\rho g Q H_{\text {pompe }}}{C_{2} \Omega_{m}{ }^{3}}
$$

Where b0, b1 and b2 are the coefficients of the hydraulic circuit; $\mathrm{C} 2$ is the the torque constant of the pump; Q is the water flow $(1 / \mathrm{min}) ; \rho$ is the density $\left(\mathrm{kg} / \mathrm{m}^{2}\right)$ and $\mathrm{g}$ is the $\operatorname{gravity}\left(\mathrm{m} / \mathrm{s}^{2}\right)$.

\section{Scalar Control Architecture}

The PV pumping system work with the sun wire and since the weather conditions (irradiance, temperature) are variable according to time, then it's necessary to adopt the operation point of the pump unit to maximum power afforded by the GPV, through the frequency of the inverter which varies the climatic conditions and it according to a scalar law strategy largely treated in the literature .A diagram of the scalar control technique is represented by figure.6. The control tool (scalar law) is the most important block of this study. The scalar control strategy has been developed with the very high description language (VHDL).As shown in figure.6, this control method is simpler and uses only one control loop and it performs the control of pump unit within the MPP tracking algorithm.

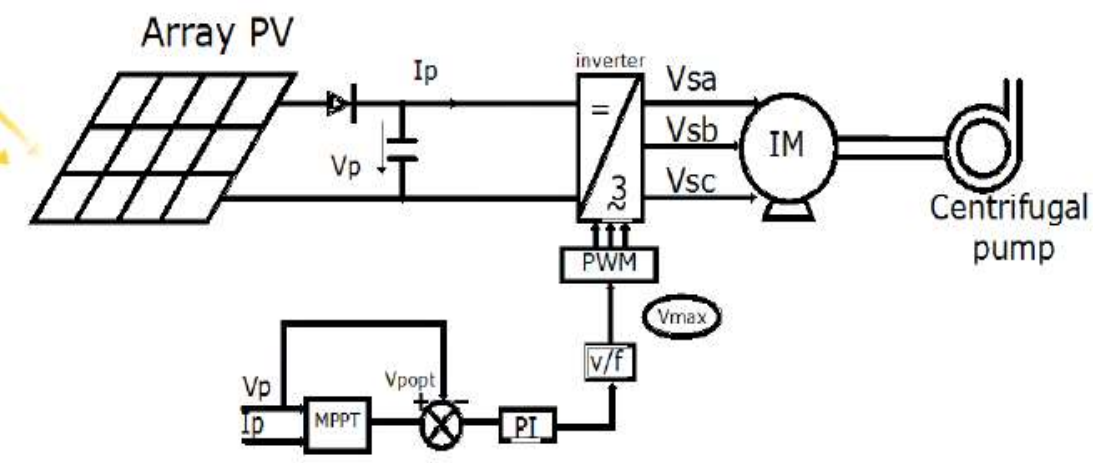

Figure 6. Scalar Control Architecture Applied to Pumping System

The architecture of the scalar control strategy consist of a pipelined structure that facilitates efficient data flow from a starting point, represented by the $\mathrm{P} \& \mathrm{O}$ algorithms to a terminal point, represented by the PWM VHDL-modules. This pipelined architecture, shown in figure.7, allows its architectural blocks to be processing in parallel, yielding much higher utilization. 


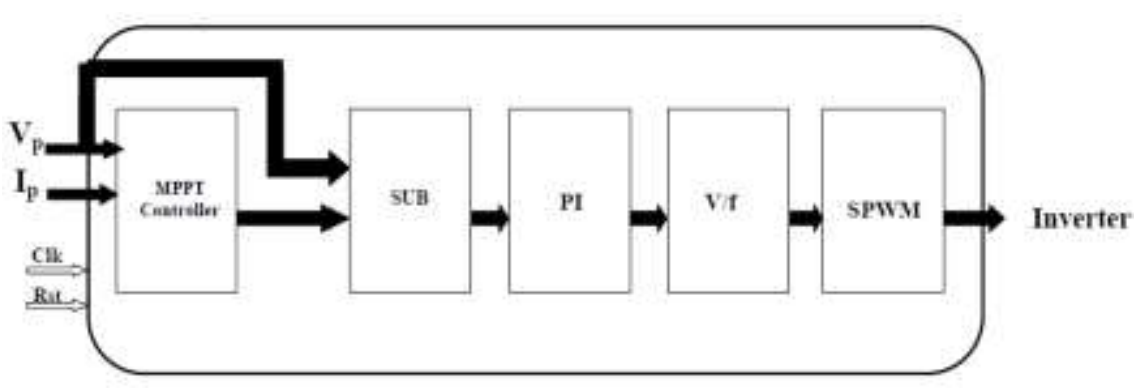

Figure 7. Pipelined System Architecture

In this section, we describe briefly the functionality and specifications of each block in the overall system architecture.

\subsection{MPPT Controller}

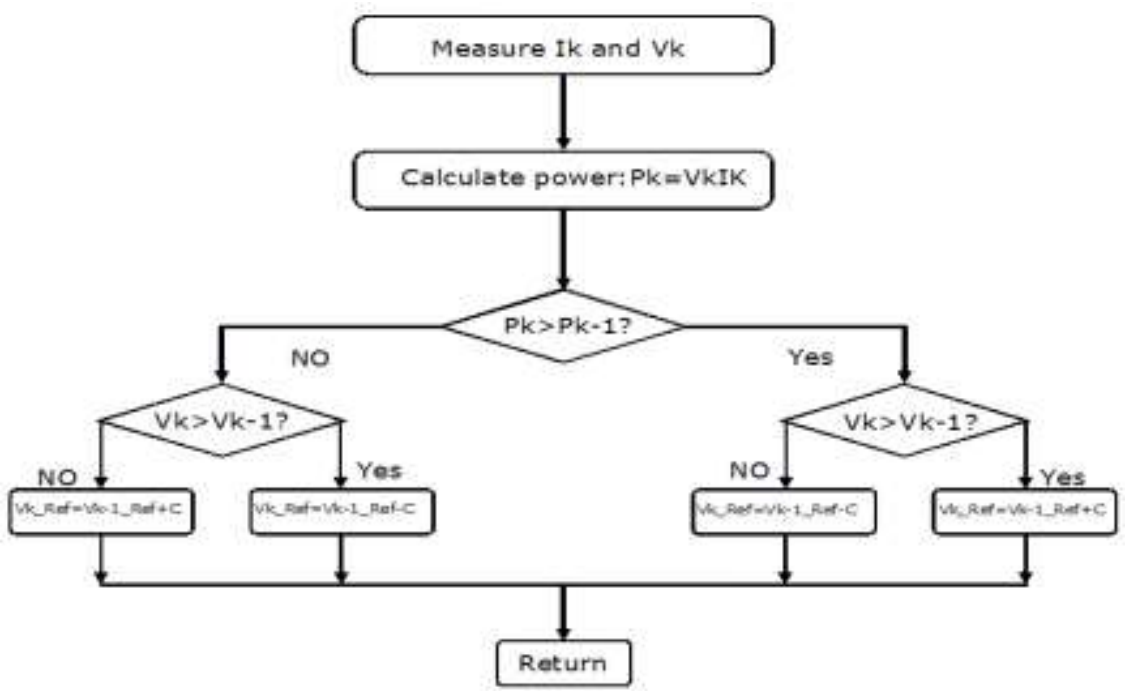

Figure 8. Perturb-and-Observe Algorithm Flowchart

As the maximum lower point (MPP) of a PV power generator depends on the climatic conditions (irradiance and temperature), it's necessary to maximize the energy delivered by the GPV. Thus it makes possible to ensure an optimum efficiency of the pumping installation Various MPP control algorithms have been proposed in literature [4]. In this work, the MPPT algorithm employed is the $\mathrm{P} \& \mathrm{O}$ algorithm. With reference to figure.8, the MPPT controller receives values or voltage and current, calculates all the necessary differentials and performs updates to Vref. Also, it stores the power, voltage and current values from the previous iteration. The advantage of the $\mathrm{P} \& \mathrm{O}$ method is that it is easy to implement [4].

\subsection{Proportional Integral Digital Controller}

Generally, a proportional integral (PI) controller is used for motor drives. For hardware implementation, the PI controller transfer function must be synthesized as a difference equation using a bilinear transfer [8]. Ts is the sampling time of the control loop.

$$
P I(z)=K p \frac{K i}{z-1}
$$

The output of the PI controller equation is then 


$$
S_{n}=S_{n-1}+K p \varepsilon_{n}-(K p-K i) \varepsilon_{n-1}
$$

The diagram of the implementation of PI controller is shown in Figure 9

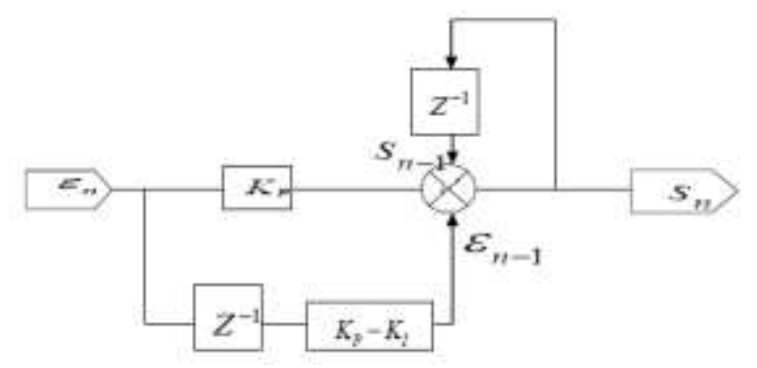

Figure 9. Implementation of a PI digital Controller

\subsection{Advanced Scalar Control}

Scalar control of an induction motor is designed as "Volt per Hertz" drive. It means that the control algorithms keep the magnetizing current (flux) of the motor constant by varying the stator voltage with frequency.

The resistant torque exerted by the centrifugal pump varies as the square of the speed. We can, without inconvenience, diminish the flow of the engine and thus the value of the motor supply voltage to a frequency lower than the nominal frequency of the principle of this control is shown in figure.

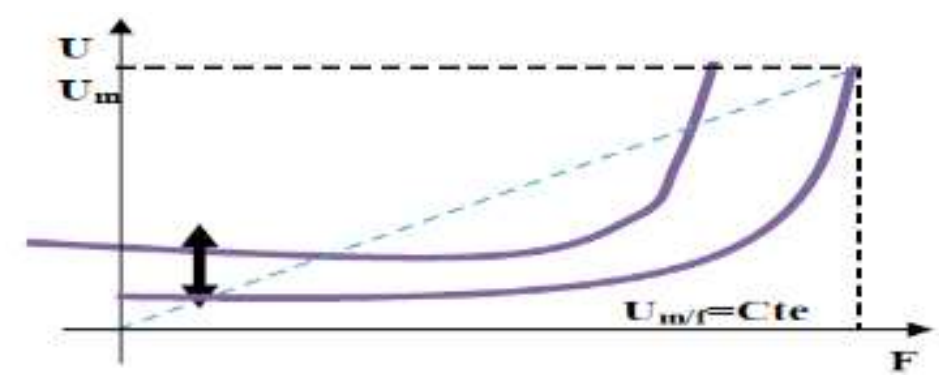

Figure 10. The Principle of Advanced Scalar Control

\section{Discussion by Co-simulation Architecture}

Under the MATLAB / Simulink environment, the simulation diagram in scalar control adopted and the elements constituting the power section of the photovoltaic system is given by the Figure 11.

The Active-HDL block including VHDL programs of each element constituting the architecture of Figure11. Numerical simulations performed on the magnitudes of the pump are given in Figure 12. We find that the electromagnetic torque establish its rated speed from $350 \mathrm{~ms}$ seen the slow dynamics of the system, it reaches a nominal value of $0.25 \mathrm{Nm}$ in standard climatic conditions $1000 \mathrm{~W} / \mathrm{m}^{2}$ and $25^{\circ} \mathrm{C}$. 


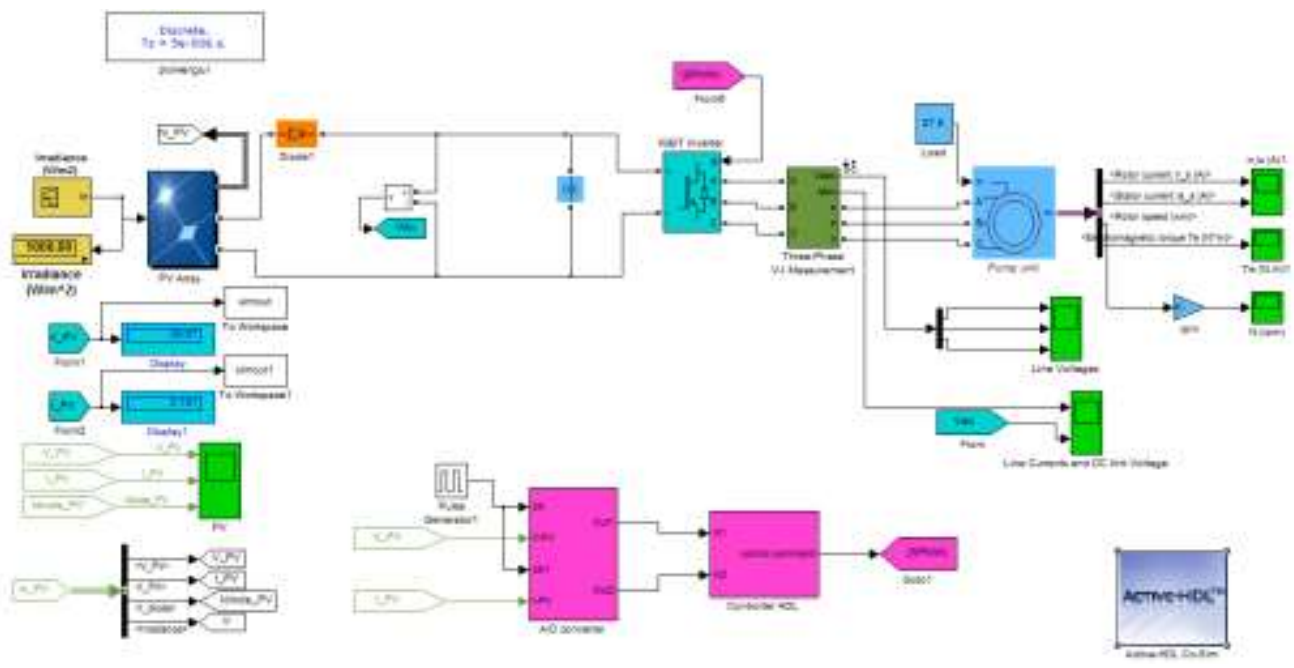

Figure 11. Co-simulation Using Matlab/Simulink and the Active-HDL Programs

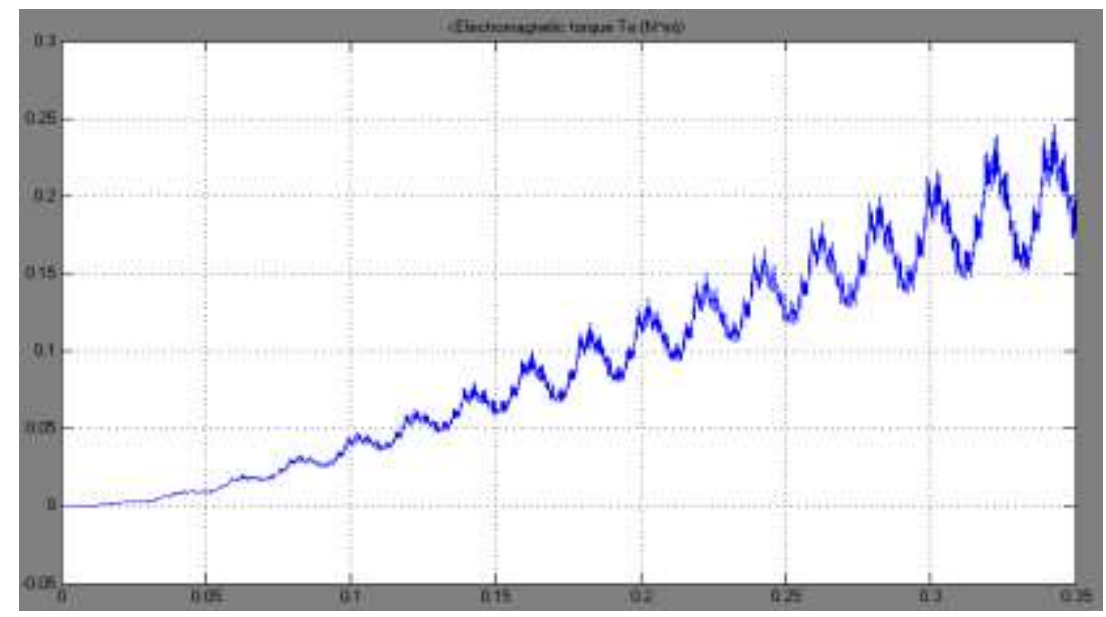

Figure 12. Electromagnetic Torque

The stator current in the three motor phases takes a nominal effective value of 3.2A, the modulating control of the Pulse Width Modulating SPWM types of inverters are applied to the arms and they are given by Figure 13 including their maximum value not exceeding $40 \mathrm{~V}$. 


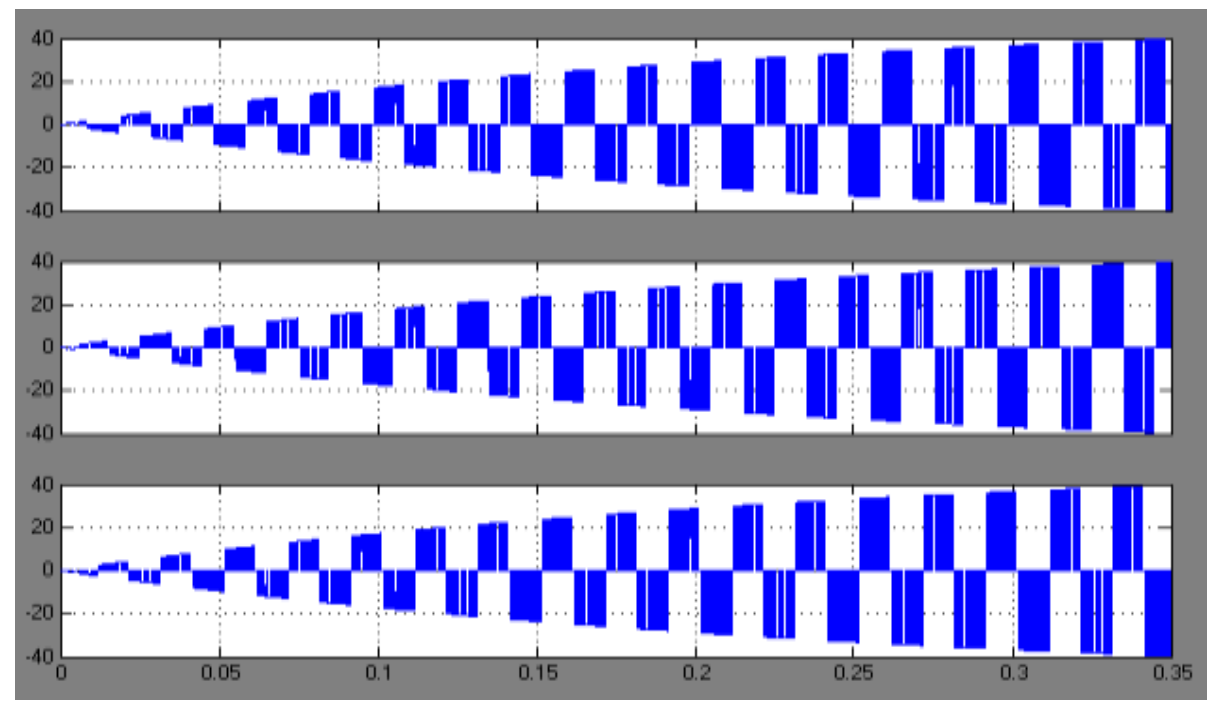

Figure 13. Modulating Control of the Pulse Width Modulating for IGBT

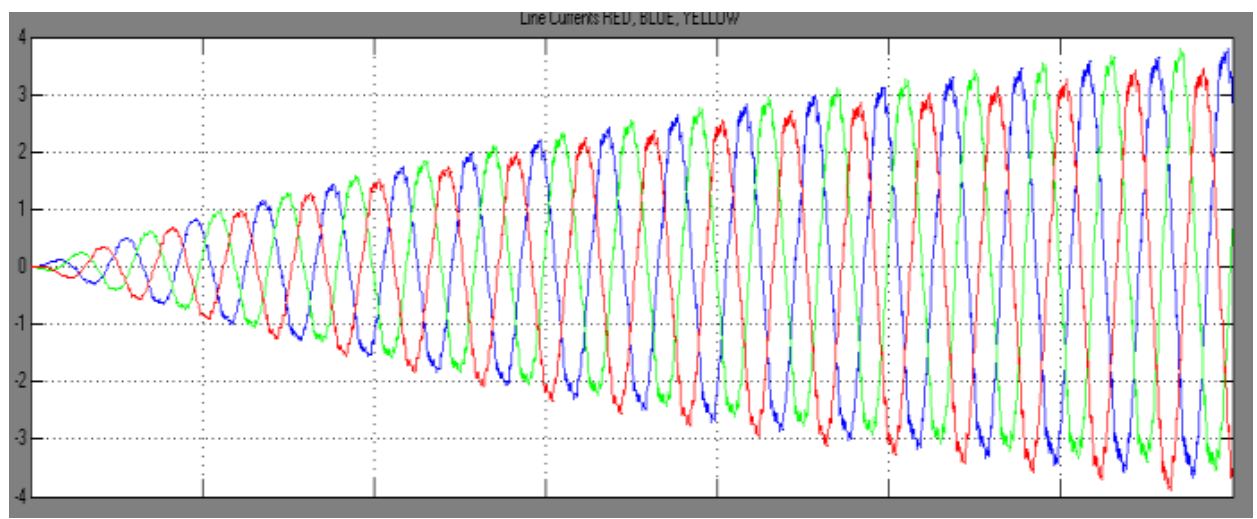

Figure 14. Static Current of the Induction Motor

\section{Implementation RTL of the Scalar Control}

The resistant torque exerted by the centrifugal pump varies as the square of the speed. We can, without inconvenience, diminish the flow of the engine and thus the value of the motor supply voltage to a frequency lower than the nominal frequency of the principle of this control is shown in figure.

Logical blocks of the HDL controller are generated by the environment of the ISE Xlinxs society and they are given by Figure 15 


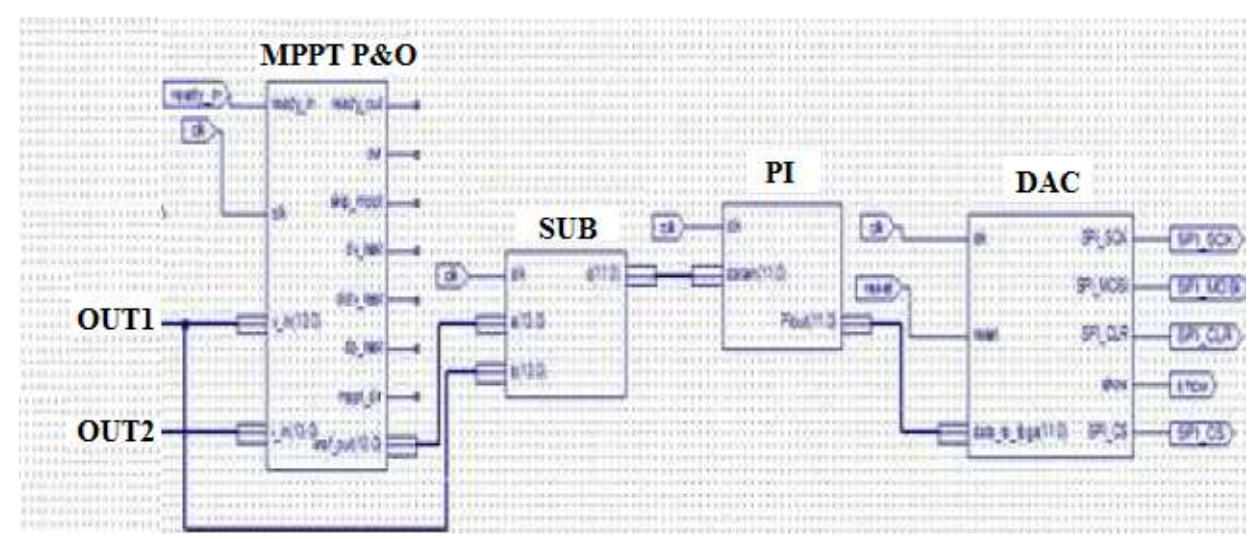

Figure 15. Logical Blocs of the HDL Controller

The signals OUT1 and OUT2 are output from the ADC as shown in Figure 14, the RTL (register transfer logic) implementation and the numerical simulation of the MPPT control $(\mathrm{P} \& \mathrm{O})$ are given in figures

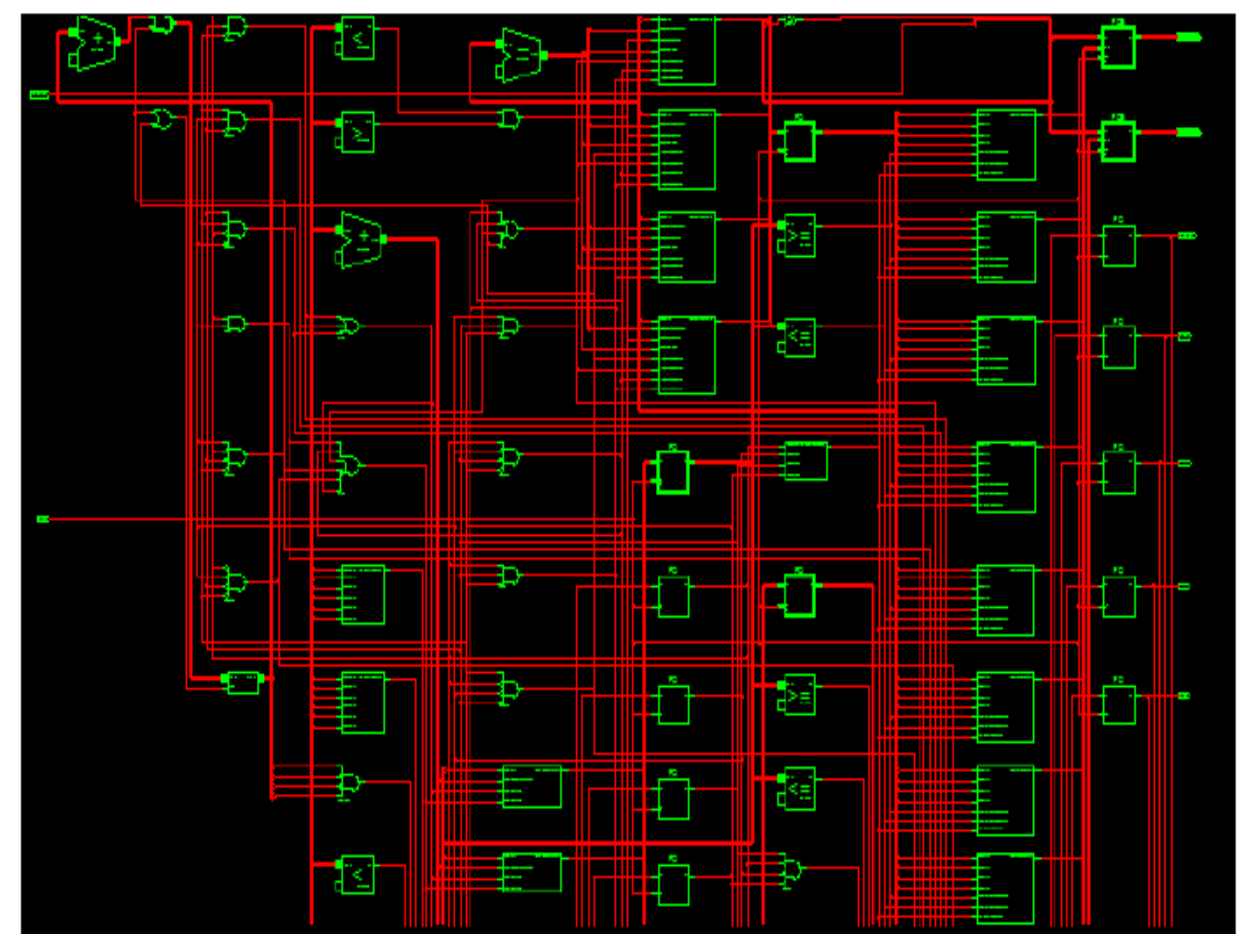

Figure 16. RTL Level of the ADC 


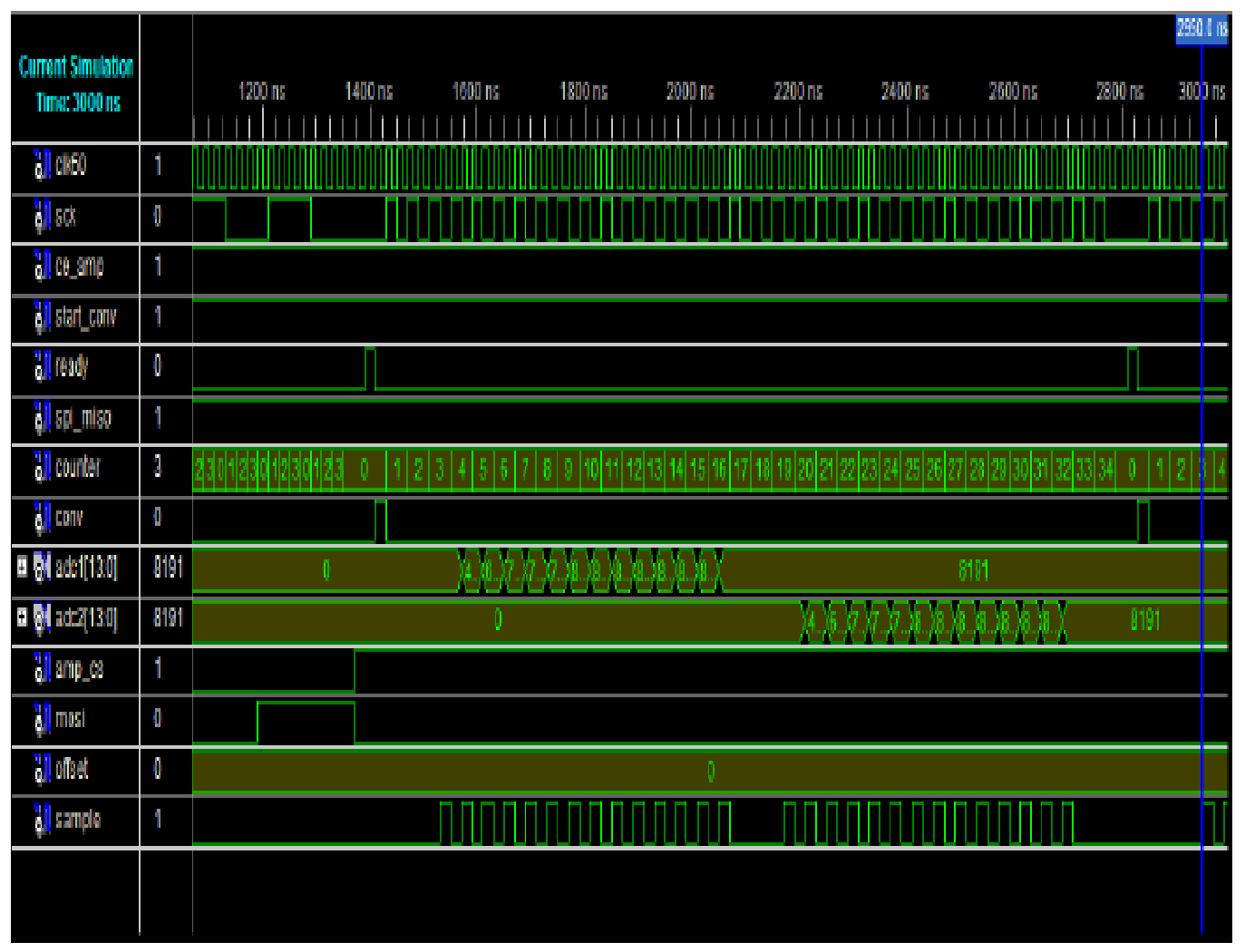

Figure 17. Simulation of the ADC

We note in Figure 2.41 the sampled analog value is converted into digital data for 34 cycles SPI_SCK clocks after a pulse signal of CONV. The converted value is then presented after the next pulse of the same CONV signal

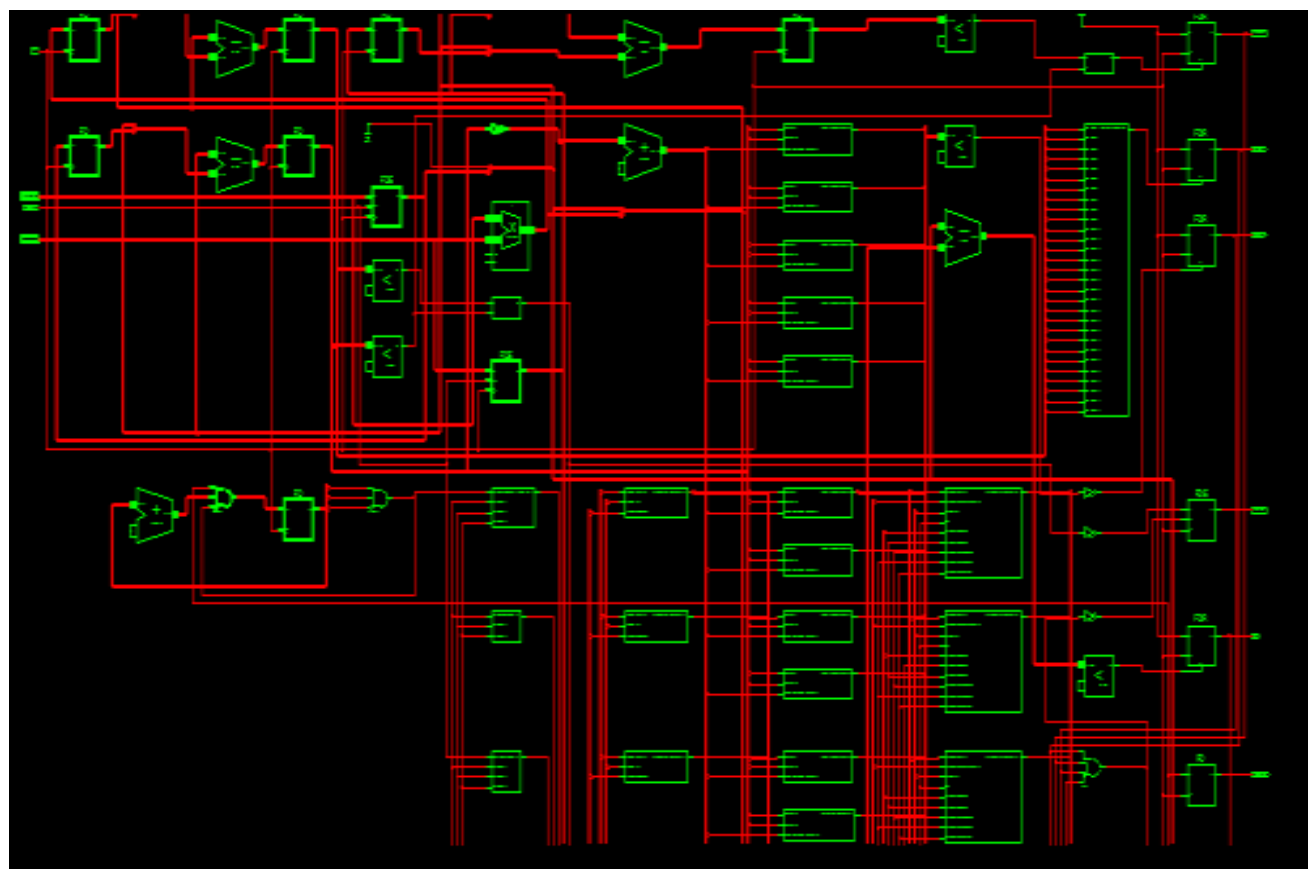

Figure 18. RTL Level of MPPT (P\&O) 


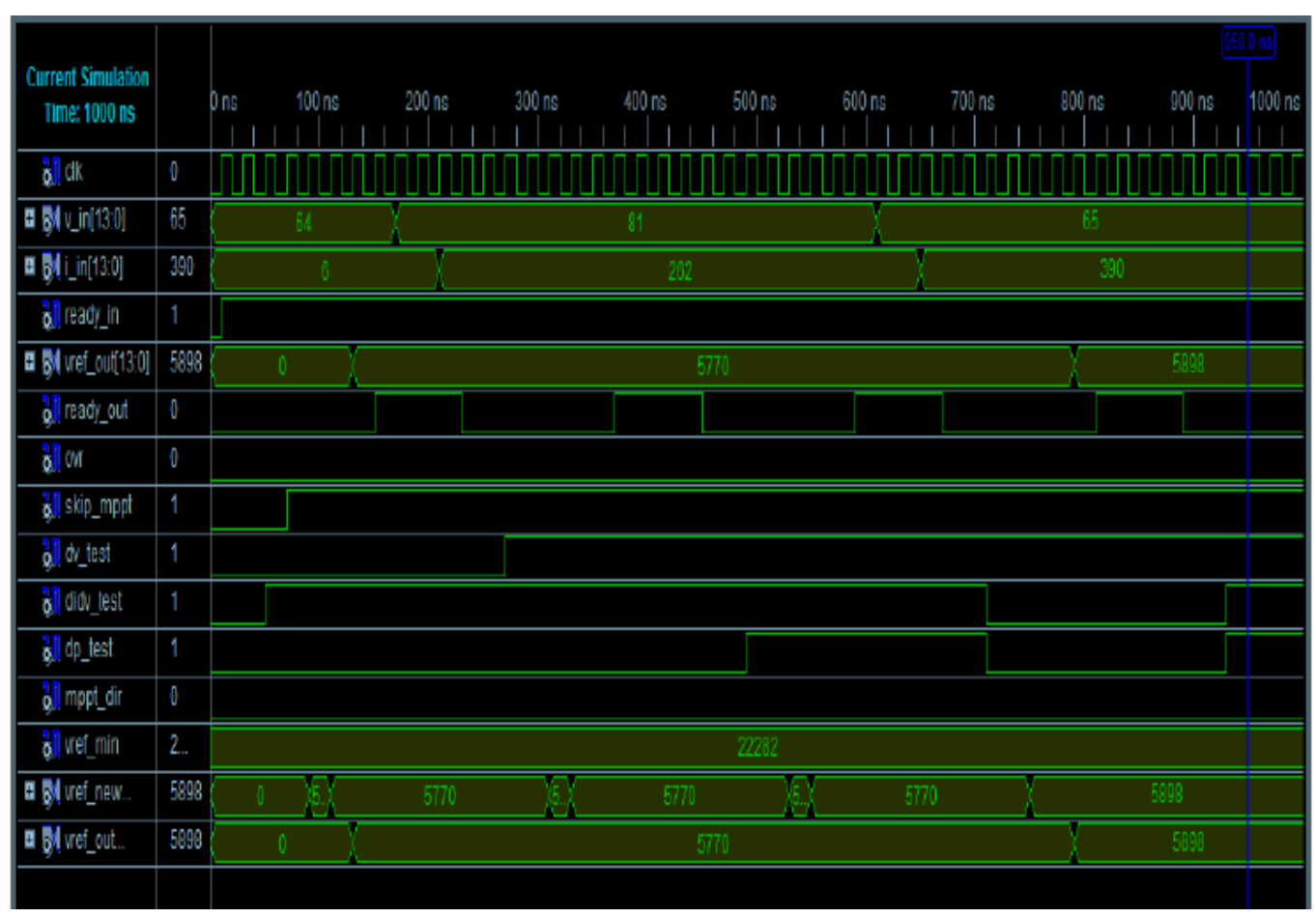

Figure 19. Simulation of MPPT (P\&O)

Figure 2.48 shows simulations MPPT controller block, which is the unit responsible for decisions regarding the maximum power point tracking. For each clock cycle or was the ready_ in signal is high, the voltage and current are read, and changes are processed to make the correct decisions as follows: Follow or not the power point on the curve and in which direction. the signals didv_test respectively, dp_test, dv_test, mppt_dir and over are internal indicators test the operation of signals used in the physical description following each treatment. They reserve to inform us on the decisions taken by the relevant algorithm. The Vrefmodified signal is sent immediately Vref_out.

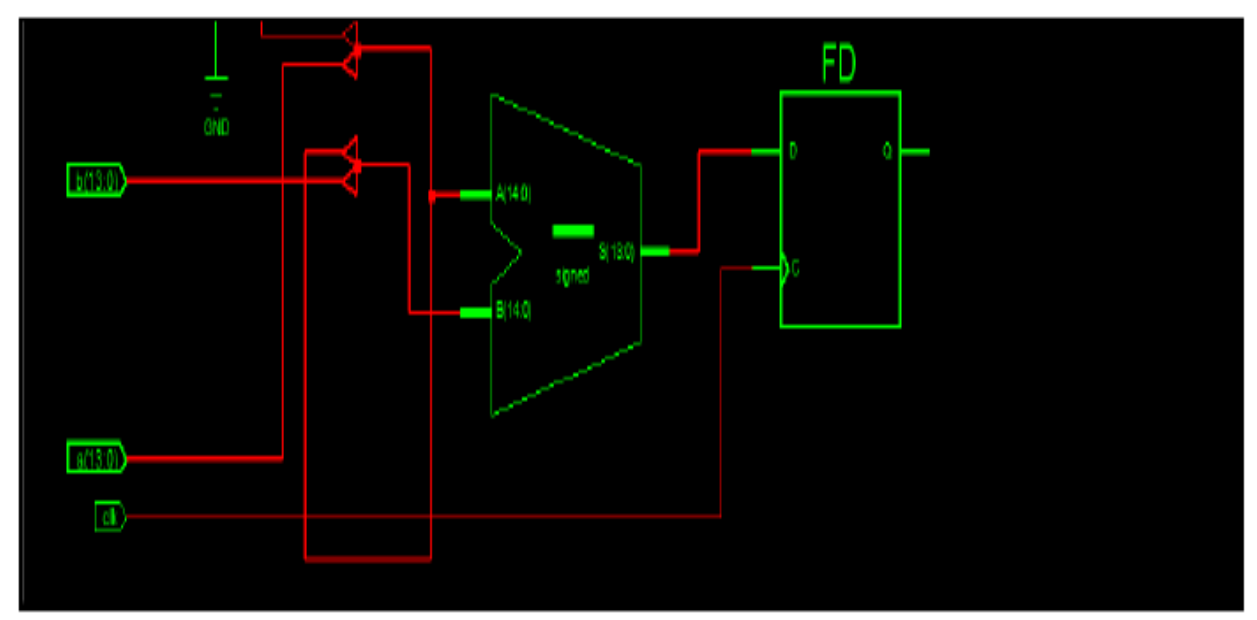

Figure 20. RTL Level for the Sub of 14 Bits 


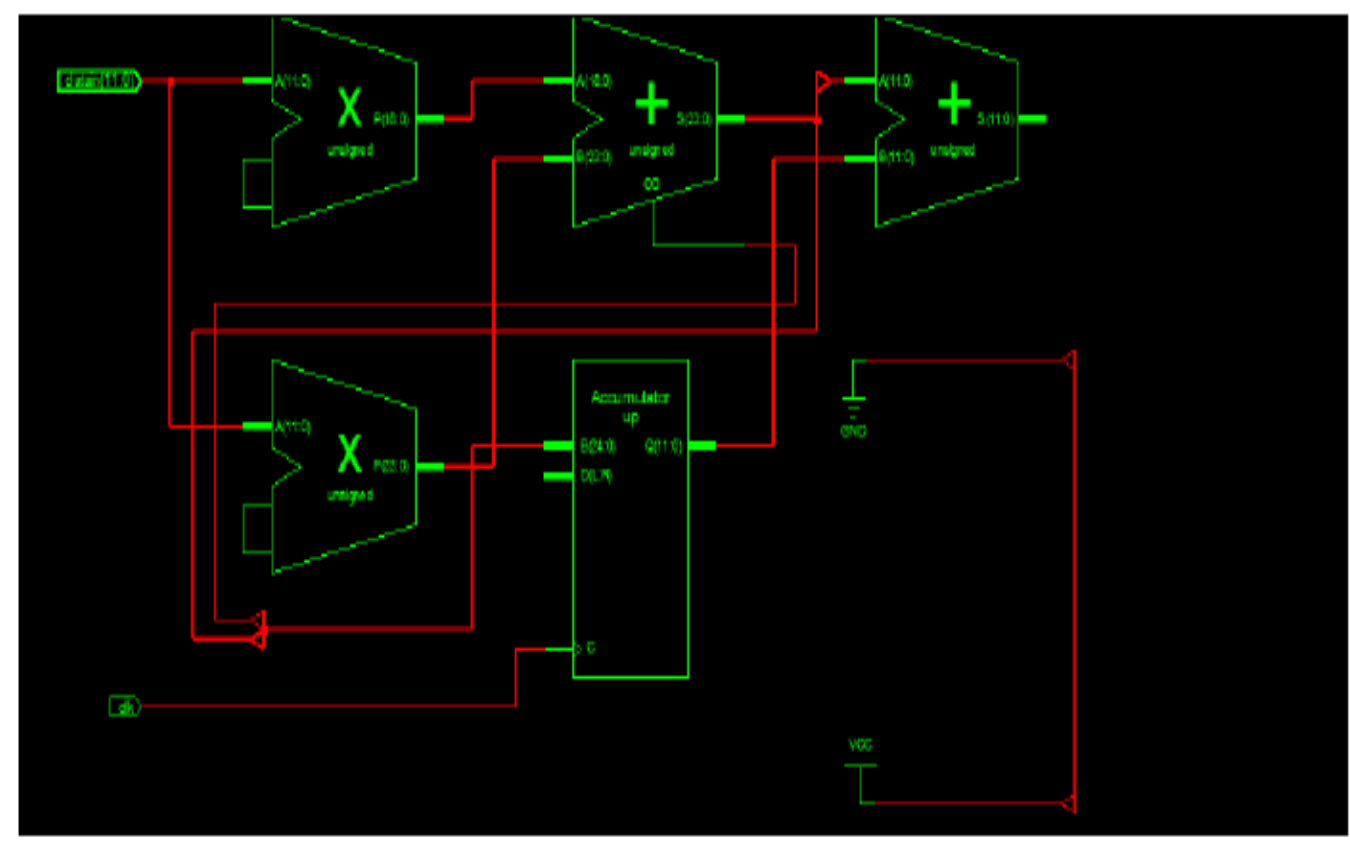

Figure 21. Level RTL of PI Controller

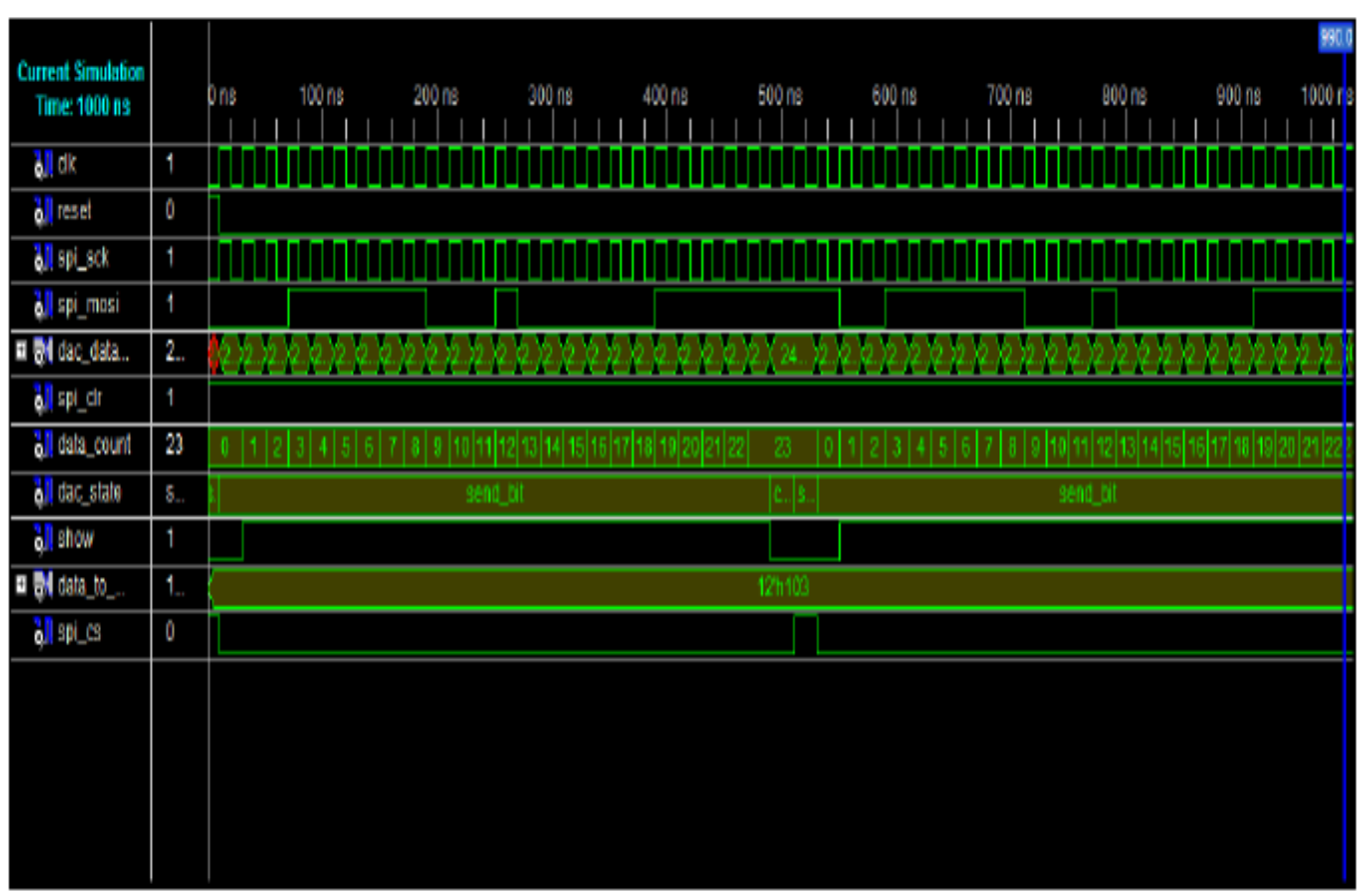

Figure 22. Simulation of the DAC

within Analog / Digital converter, the SPI interface is formed by a 24-bit shift register. Each 24-bit control word is composed of a command and an address followed by a numerical data. Depending on the selected order, FPGA circuit selects all or a converter output channels Digital / Analog via a 4-bit address. according with the address field, the FPGA sends an unsigned 12-bit digital data as the converter Digital / Analog converts it to an analog value of the selected output. 


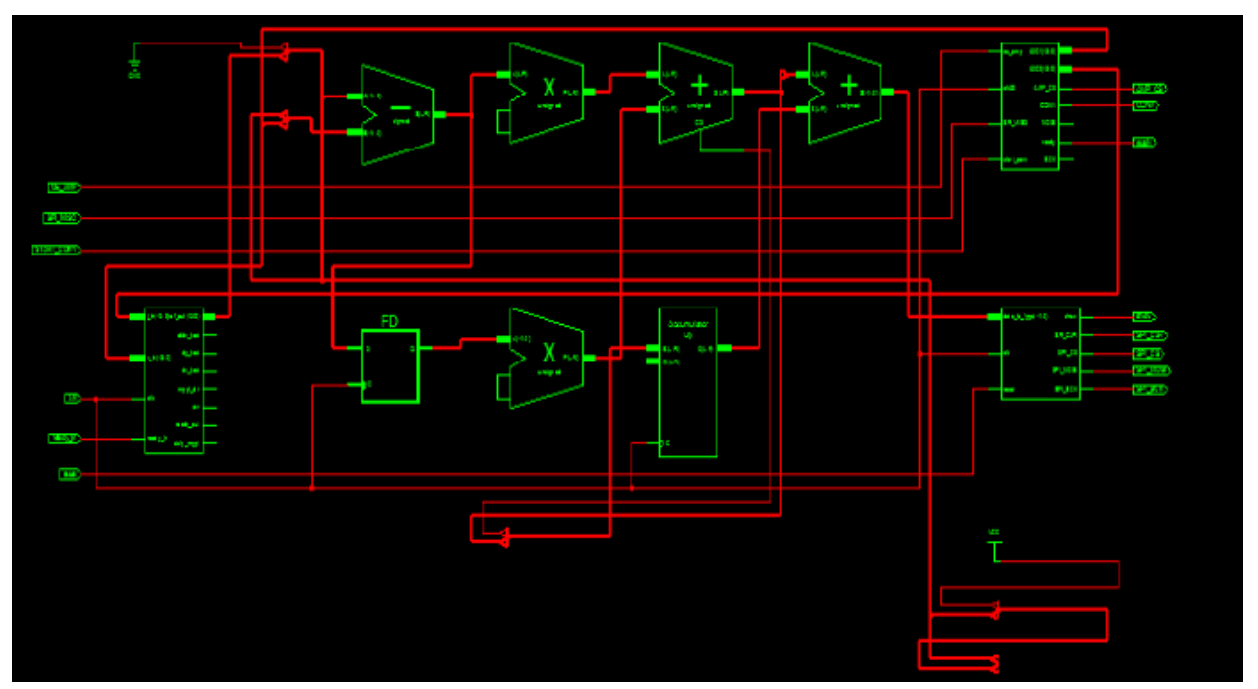

Figure 23. RTL Level of the Scalar Control

After conducting the synthesis of our order. It is considered necessary to present the resource consumption report for the case of our control adopted. Indeed, the ISE environment provides us with a detailed report on the material resources consumed given by Figure 24 . We note that $31 \%$ of material resources are used in the Spartan FPGA card.

Table 1. Material Resources of Scalar Control on FPGA

\begin{tabular}{|c|c|c|c|}
\hline \multicolumn{4}{|c|}{ Device Utilization Summary (estimated values) } \\
\hline Logic utilization & Used & Available & utilization \\
\hline Number of Slices & 263 & 5888 & $4 \%$ \\
\hline Number of Slices Flip Flops & 277 & 11776 & $2 \%$ \\
\hline Number of 4 input LUTs & 395 & 11776 & $3 \%$ \\
\hline Number of bonded IOBs & 14 & 372 & $3 \%$ \\
\hline Number of MULT18X18SIOs & 3 & 20 & $15 \%$ \\
\hline Number of GCLKs & 1 & 24 & $4 \%$ \\
\hline
\end{tabular}

\section{Conclusion}

This work presents the simulation of a photovoltaic pumping system which has an induction motor driven by a three- phase's voltage converter. The pulses to command the DC-AC converter technique are generated by a virtual FPGA device. The global system was simulated using the Matlab/Simulink and the Active-HDL programs. The Matlab/Simulink allows performing the system dynamics while the Active-HDL runs a program written language. In general, the algorithm (VHDL) verification is done testing it separately with specifics inputs (manual inspection). The objective of this simulation done in this paper allows the rapid development of the program done the possibility to test this code in a virtual prototype of the system, reducing the risk of significant changes in the code for one future implementation in hardware. Another great advantage is the portability and flexibility of the simulation tool. 


\section{Appendix}

The Generator PV :

$\mathrm{E}_{\mathrm{g}}=1.7910^{-19} \mathrm{~J}, \mathrm{I}_{\mathrm{cc}}=1.19 \mathrm{~A}, \mathrm{n}_{\mathrm{t}}=630.97, \mathrm{I}_{\mathrm{s}}=1.502410-2 \mathrm{~A}, \mathrm{E}_{0}=1000 \mathrm{~W} / \mathrm{m} 2, \mathrm{~T}_{0}=25^{\circ} \mathrm{C}$, $\mathrm{T}_{\mathrm{p} 0}=56.26^{\circ} \mathrm{C}$.

Induction motor :

$\mathrm{R}_{\mathrm{s}}=24.6 \Omega, \mathrm{R}_{\mathrm{r}}=16.1 \Omega, \mathrm{L}_{\mathrm{m}}=1.46 \mathrm{H}, \mathrm{L}_{\mathrm{r}}=1.48 \mathrm{H}, \quad \mathrm{Ls}=1.49 \mathrm{H}$

Centrifugal pump :

$\mathrm{C}_{2}=7.510^{-6} \mathrm{Kg} \cdot \mathrm{m}^{-4} \cdot \mathrm{s}^{-2}, \mathrm{~b}_{0}=4.5210^{-4} \mathrm{~min}^{2} \cdot \mathrm{m} \cdot \mathrm{tr}^{-2}, \mathrm{~b}_{1}=-1.96610^{-3} \mathrm{~m} \cdot \mathrm{min}^{2} \cdot \mathrm{tr}^{-1} \cdot \mathrm{L}^{-1}, \mathrm{~b}_{2}=-0.012$ $\min ^{2} \cdot \mathrm{m} \cdot \mathrm{L}^{-2}, \Psi=4.081610^{-3} \mathrm{~min}^{2} . \mathrm{m} \cdot \mathrm{L}^{-2}$

\section{References}

[1] A. Mellit, H. Rezzouk, A. Messai and B. Medjahed, "'-based real time implementation of MPPTcontroller for photovoltaic systems", Renewable Energy, vol. 36, (2011), pp. 1652-1661.

[2] M. Messaoud, F. Messai and H. Benalla, "Vectorial command of induction motor pumping system supplied by a photovoltaic generator", Journal of electrical engineering, vol. 62, no. 1, (2011), pp. 3-10.

[3] M. Arrouf, and S. Ghabrour, "Modelling and simulation of a pumping system fed by photovoltaic generator within the Matlab/Simulink programming environment", Desalination, vol. 209, (2007), pp. 23-30.

[4] AF. Boehinger, "self adaptive DC converter for spacecraft power supply", IEEE Transaction on Aerospace and Electronic system, (1968), pp.102-211.

[5] M. Sun Ryu, and J. Jang, "Enhanced efficiency of organic photovoltaic cells using solution-processed metal oxide as an anode buffer layer", Solar Energy Materials and Solar Cells. vol. 95, no. 11, (2011), pp. 3015-3020.

[6] BAHT, S. R. Pittet, A and Sonde, BS. "Performance Optimisation of Induction Motor-Pump using Photovoltaic Energy Source”, IEEE Trans Industrial Applications, vol. 23, no. 6, (1987), pp. 995-1000.

[7] C.L.P. Swamy, B. Singh and B.P. Singh, "Dynamic Performance of a Permanent Magnet DC Motor Powered by a PV Array for Water Pumping", Solar Energy Mat Solar Cell, vol. 36, no. 2, (1995), pp. 187-200.

[8] D. Mezghani and A. Mami, "Bond graph modelling and improved V/F control of pumping photovoltaic installation, simulations and measurements", Proceeding of the International conference on Sciences and Techniques of Automatic control \& computer engineering, Hammamet, Tunisia, 20-22 December, (2009),pp. 1274-1285.

[9] R. Dubey, "Introduction to Embedded System Design Using Field Programmable Gate Arrays, Springer-Verlag London Limited, (2009).

[10] MF. Castoldi, ML. Aguiar, AAO Junior and JRBA Monteiro, "A Rapid Prototype Design to Investigate the FPGA Based DTC Strategy Applied to the Speed Control of Induction Motors", Proceeding of the IEEE International Conference on Industrial Technology, Mumbai, India, 15-17 December, (2006), pp. 955-960.

[11] MF. Mimouni, MN. Mansouri, B Benghanem, and M. Annabi, "Technical note Vectorial command of an asynchronous motor fed by a photovoltaic generator', Renewable Energy, vol. 29, (2004), pp. 433442.

[12] E. Koutroulis, K. Kalaitzakis and N.C. Voulgaris, "Development of a Microcontroller-Based, Photovoltaic Maximum Power Point Tracking Control System", IEEE Transaction on Power Electronics, vol.16, no.1, (2001), pp. 46-54.

[13] I. Houssamo, F. Locment and M. Sechilariu, "Maximum power tracking for photovoltaic power system: Development and experimental comparison of two algorithms", Renewable Energy, vol.35, (2010), pp. 2381-2387.

[14] C. Larbes, S.M. Ait Cheilkh, T. Obeidi and A. Zerguerra, 'Genetic algorithms optimized fuzzy logic control for the maximum power point tracking in photovoltaic system', Renewable Energy, vol. 34, (2009), pp. 2093-2100.

[15] Olorunfemi, O. "Analysis of current source induction motor drive fed from photovoltaic energy source' IEEE Transaction on Energy Conversion, vol. 6, no. 6, (1991), pp. 99-106.

[16] A. Mukerjee, R Karmakar and A.K. Samantaray, "Modelling of basic induction motors and source loading in rotor-motor systems with regenerative force field", Simulation Practice Theory, vol. 7, (1999), pp. 563-576.

[17] G.E. Ahmad, HMS Hussein and H. El-Ghetan, "Theoretical analysis and experimental verification of PV modules'. Renewable Energy, vol. 28, (2003), pp. 1159-1168. 


\section{Authors}
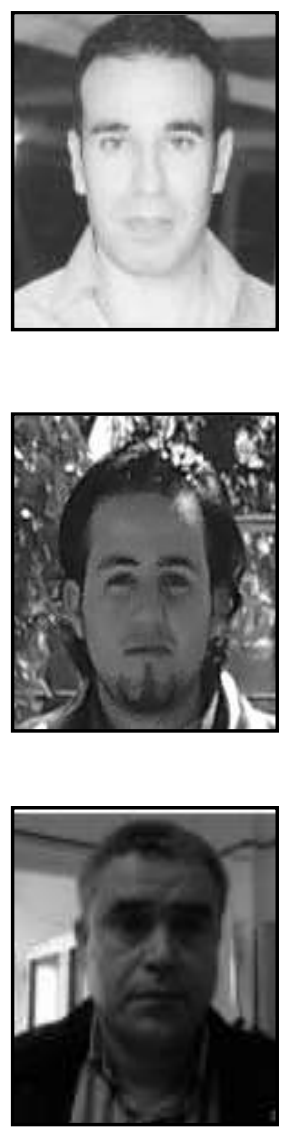

Dhafer Mezghani, was born in Tunisia. He received his Ph.D. in electrical engineering at the National School of Engineers of Tunis in 2009. He is an assistant-master at National School of Computer Science and it operates in the field of electronics and microelectronics for embedded systems design (FPGA, microcontrollers) Also, its research affect the bond graph modeling, analyze and control of Renewable Energy systems (photovoltaic and wind) at the Faculty of Sciences of Tunis.

Hichem Othmani, was born in Tunisia. He received master degrees in electronics from the Faculty of Sciences of Tunis in 2012. Between 2013 and 2014, he occupies a temporary technologist position at Higher Institute of Technological Studies of Zhagwen (Tunisia). Actually, he is a PhD student in electronics in the Faculty of Sciences of Tunis. He works on Fuzzy logic control, Photovoltaic Systems, optimization of the law controls by intelligent technics and its implementation on a embedded design.

Abdelkader Mami, was born in Tunisia. He is a Professor in Faculty of Sciences of Tunis (FST). He received his Dissertation H.D.R (Enabling to Direct of Research) from the University of Lille (France) 2003, he is a member of Advise Scientific in Faculty of Science of Tunis (Tunisia). 
International Journal of Control and Automation

Vol. 10, No. 5 (2017) 